\title{
A formação da sociedade Argentina contemporânea. Sociedade e trabalho entre 1880 e 1920
}

\author{
Norberto O. Ferreras*
}

\section{Resumo:}

O presente trabalho tem como objetivo apresentar as relações existentes entre a formação do movimento operário na Argentina com a conformação da Argentina moderna. Os imigrantes e a transformação dos mesmos em trabalhadores levou o Estado a tomar uma série de providências para incorporar esse grupo ao interior da própria sociedade. Isso não foi possível sem a luta operária e sem o reconhecimento do seu lugar na sociedade. De alguma forma a incorporação dos trabalhadores acabou enclausurando as tentativas de restauração do Estado Oligárquico.

Palavras-chaves: Argentina, Trabalhadores, Legislação, Repressão.

Entre 1880 e 1920 a Argentina se transformou profundamente. Num breve repasso das mudanças é interessante apontar que a Argentina passou de um país com enormes dificuldades para consolidar o Estado Nação, com até duas sedes rivais para o governo nacional, a um dos poucos países latino-americanos com uma democracia de massas consolidada; deixou de ser um país voltado para dentro e se inseriu plenamente nas trocas econômicas, sociais, políticas e culturais de um mundo cada vez mais interrelacionado; de um país pobre alcançou o status de país abastado com avançados indicadores sociais, que não só superavam os dos seus vizinhos, como também a vários dos principais países europeus; foi um dos poucos países onde a imigração modificou profundamente o quadro demográfico; e deixou de ser uma sociedade agrária para ser uma sociedade urbana. $\mathrm{O}$ que mais nos interessa neste artigo são os trabalhadores da Argentina, que, embora continuaram a ser um grupo heterogêneo, em 1920 esse matiz não era um empecilho para que a sua presença não fosse considerada pelas autoridades e pelas classes dominantes. Certamente a consideração não implicava o respeito pelas suas necessidades e interesses, e sim o descaso e muitas vezes a repressão.

Em grande medida os trabalhadores foram os que forçaram uma série de mudanças nessa sociedade e foram os que obrigaram aos governantes a se defrontar com o futuro que eles próprios tinham planejado durante os longos anos da organização nacional. De fato, pensadores e políticos como Esteban Echeverría, Juan Bautista Alberdi e Domingo Faustino Sarmiento tinham diagnosticado a imigração de massas 
como a única possibilidade para a transformação sociocultural da Argentina. ${ }^{1}$ Segundo estes pensadores e políticos, os imigrantes teriam que transformar-se em produtores rurais de médio porte. Ao estar impelidos pelo afã de lucro estes produtores de porte médio alavancariam a economia da Argentina, formando uma classe média rural, a qual, para defender os seus interesses, participaria da vida política da Nação, desbancando as velhas oligarquias do poder e modernizando as estruturas políticas e sociais.

Ainda quando a imigração de massas foi um componente importante na sociedade argentina, as conseqüências não foram e não podiam ser as esperadas. $\mathrm{Na}$ medida em que as oligarquias se apropriavam das melhores terras e deixavam aos imigrantes algumas poucas terras e todo o trabalho, o resultado devia ser diferente. Se muitos imigrantes se afixaram no setor rural, a maioria dos recém-chegados optou pelas cidades, passando a conformar a classe trabalhadora, um novo grupo social que não estava nos planos dos fundadores. A saída foi aceitar a presença dos imigrantes, agora como trabalhadores, e tentar transformá-los em cidadãos antes que eles se organizassem de alguma outra forma. As consequiências não desejadas da imigração levaram à retificação dos projetos iniciais da classe dominante, que se perguntavam sobre a melhor forma de lidar com esse grupo de recém-chegados.

Desde a consolidação definitiva da ordem republicana no biênio $1880-1881^{2} \mathrm{e}$ até a virada do século o trabalho não foi uma questão importante. Para a denominada Geração de 1880 existiam outras urgências e adversários políticos bem mais importantes que os poucos trabalhadores que pensavam em reivindicar novos direitos e organizar os seus reclamos, como as lideranças frustradas com os acordos políticos existentes.

Com o crescimento econômico continuado e as altas taxas de lucro as elites ficaram a resguardo de qualquer tipo de conflito. Salvo alguma crise econômica e política ocasional, como a de 1890, nenhuma nuvem aparecia para alterar o roteiro estabelecido pelos fundadores do modelo de agroexportação. ${ }^{3} \mathrm{O}$ imigrante urbano prestava os seus serviços para uma sociedade com mão-de-obra escassa e se contentava com os benefícios alcançados, que eram altos se comparados com o local de saída. É evidente que sempre podia acontecer uma ou outra manifestação de descontentamento. Dessa forma parecia existir um problema potencial, mas não um problema real. Tanto que até os socialistas mais combativos ficavam sem incentivos para mobilizar os poucos trabalhadores. $^{4}$ 
De fato, as amplas possibilidades que se abriam aos recém-chegados não faziam deles um problema, e sim uma solução, pelo menos até 1900. Os imigrantes tanto eram trabalhadores quanto empreendedores. A visão que as elites tinham sobre os imigrantes pobres podia não ser muito favorável, mas isso não fazia deles um problema grave. Reclamava-se do modo de viver, o lazer e a imitação dos costumes e comportamentos das 'pessoas de bem', como as elites se chamavam a si próprias. As famílias abastadas reclamavam tibiamente, como aconteceu em 1868 com um baile organizado pelos sapateiros bascos de Buenos Aires. No cúmulo do desrespeito, as domésticas foram dançar vestidas com roupas iguais às de suas senhoras. ${ }^{5}$

$\mathrm{Na}$ realidade as reclamações eram mais estéticas do que políticas e mesmo olhares extremamente críticos não tinham propostas melhores que a imigração, quando muito a possibilidade de mudar os principais fluxos migratórios. Para as classes dominantes os imigrantes eram rudes, não muito bem apessoados e sujos, mas eram necessários e, além do mais, europeus. Portanto, mais cedo ou mais tarde, terminariam se submetendo à corrente principal da civilização, representada pelos setores mais abastados da sociedade.

Em vários romances deste período os imigrantes são questionados, eles seriam portadores de valores negativos e de um alto potencial de desagregação da sociedade argentina, produto das suas ambições e desrespeito pelas pautas de deferência entre as classes preexistentes. Ao mesmo tempo, os imigrantes que chegavam não eram os desejados por Sarmiento e Aberdi. Esses italianos e espanhóis não podiam ser comparados com os almejados imigrantes nórdicos ou saxões, pelo contrário, carregavam os elementos negativos e os defeitos das suas sociedades. Ao mesmo tempo, pelo fato de a grande maioria dos imigrantes se concentrar praticamente em duas nacionalidades, os membros das elites duvidavam das possibilidades de sua integração e temiam pelo aparecimento de cistos sociais dentro do corpo nacional. E ainda havia imigrantes vistos como mais perigosos, como os judeus, que podiam ser fatores de conflitos entre religiões e eram um corpo estranho dentro da uniformidade católica. Fossem estes imigrantes simples trabalhadores, profissionais consagrados ou empresários bem-sucedidos, nenhum deles conseguia desvencilhar-se dos preconceitos estabelecidos por distintos setores da sociedade da Argentina. Romancistas como Eugenio Cambaceres, ${ }^{6}$ Antonio Argerich ${ }^{7}$ e Julián Martel $^{8}$ são representantes deste tipo de escrita e da exposição dos preconceitos da elite portenha. No caso de Julián Martel, 
ainda temos a presença do anti-semitismo, que responsabilizava aos judeus pela crise econômica de 1890.

Uma outra forma de ver os imigrantes neste período, que tem sido avaliada como uma visão positiva destes, carrega uma carga similar de preconceito e desprezo. Adolfo Saldías e Alberto Gerchunoff, autores, respectivamente, de Bianchetto e Los Gauchos Judios, são exemplos de uma corrente denominada "xenófila". 9 Ambos mostram como o imigrante da Itália ou da Europa Central são bons e úteis ao crescimento da Argentina, na medida em que aceitam os costumes e as formas de vida locais. Certamente são portadores dos valores da ética do trabalho e da honestidade e alcançam o êxito mesmo onde os nacionais não conseguem. Mas a vitória é produto da aceitação da idiossincrasia local unida aos valores próprios dos imigrantes. O título do livro de Gerchunoff é mais do que revelador.

O que fica evidenciado nesta visão é a assimilação e aceitação do projeto da Geração de 1837, e que foi posteriormente adaptado e posto em prática pela Geração de 1880. Segundo esta forma de ver a imigração, o imigrante seria útil na medida em que ocupa e trabalha a terra, mas também, sempre que se adapta às condições locais e à cultura existente, principalmente no que toca à deferência com as classes dominantes.

Mas, à medida que nos aproximamos da virada do século, esta forma de compreender a imigração foi mudando e os preconceitos passaram a estar presentes na política argentina. Certas tendências já existentes no período anterior cobraram força, tornando-se cada vez mais influentes. Estas tendências, que viam na imigração algum tipo de ameaça à integridade nacional, passaram a valorizar o trabalhador nacional em prejuízo do imigrante, questionando a imigração e vendo em cada imigrante um inimigo em potencial. Aos poucos os imigrantes foram vistos como os responsáveis pelos conflitos existentes na sociedade argentina. De fato, para 1902 foi sancionada a "Lei de Residência" que permitia a expulsão dos imigrantes indesejáveis e conflituosos. A questão é por que aconteceu esta mudança? Por que se passou de uma política de convívio e tolerância a outra de hostilidade e desconfiança?

Em grande medida o que tinha mudado na sociedade argentina desse período foi o surgimento de um movimento reivindicativo por parte dos trabalhadores. Se até 1900, aproximadamente, os trabalhadores estavam totalmente desorganizados e sem nenhuma instituição que consegue reunir as reclamações dos operários, desde 1901 contaram com a Federación Obrera Argentina (FOA). ${ }^{10}$ Esta Federação, que reunia os trabalhadores das mais diversas tendências existentes no interior do operariado, teve como principal 
objetivo a organização das lutas operárias em prol da ampliação dos direitos trabalhistas e a defesa contra os abusos patronais ou dos proprietários de moradias de aluguel. Até esse momento trabalhadores e patrões tinham convivido em associações por ofício e este foi o momento decisivo no processo de conformação de um novo setor na sociedade argentina, obrigando, portanto, que o conjunto da sociedade se posicionasse ante este novo setor e ante a exposição das suas necessidades.

À medida que a taxa de lucro das exportações decrescia e que aumentava o exército de reserva, os trabalhadores ficavam cada vez mais expostos às vicissitudes do mercado. Os trabalhadores que no período anterior conseguiam bons salários e emprego garantido no campo e na cidade, passaram a defrontar-se com um mercado de trabalho cada vez mais saturado, com a queda dos salários reais, e, conseqüentemente, com a queda do poder aquisitivo. Por meio da imigração, todos os anos chegavam a Buenos Aires quantidades significativas de novos trabalhadores, e essa chegada não correspondia às necessidades do mercado de trabalho local, e sim às expectativas dos imigrantes. ${ }^{11}$ Os trabalhadores de Buenos Aires compreenderam que a única forma para melhorar as suas condições de vida estava no caminho da organização e do confronto com os patrões, com os comerciantes dos produtos de primeira necessidade e com os donos das moradias operárias.

Era evidente que a sociedade argentina tinha mudado significativamente desde a consolidação do Estado Nação no biênio 1880-1881. A população passou de aproximadamente 1,77 milhões em 1869 para 7,48 em 1914. Mas o número isolado mais significativo foi o do crescimento da cidade de Buenos Aires, que passou de 187 mil habitantes em 1869 para 664 mil em 1895, alcançando os 1,575 milhões em 1914. ${ }^{12}$ Ou seja, a população de Buenos Aires cresceu mais de 8 vezes em pouco mais de 40 anos, sendo que na última década tinha mais que duplicado. Ao mesmo tempo crescia o desemprego masculino e cada vez mais mulheres e crianças ingressavam no mercado de trabalho para compensar as taxas de desemprego e os aumentos no custo de vida das famílias operárias. ${ }^{13}$

A mudança principal na sociedade argentina da virada do século foi $o$ comportamento dos trabalhadores: a passividade foi substituída pela ação. Se a em 1901, como mencionamos, foi criada a Federación Obrera Argentina ${ }^{14}$, isto não foi produto de uma mudança espontânea e repentina por parte dos trabalhadores e se foi o acumulo de experiências prévias por parte dos mesmos, a mudança no mercado de trabalho foi fundamental para a nova atitude coletiva. Esta nova atitude se refletiu num 
aumento no nível de militância e na cada vez mais violenta atividade política operária. Contrariando a vontade da elite portenha, em 1904 o Partido Socialista conseguiu eleger Alfredo Palacios primeiro deputado socialista, pelo bairro operário de La Boca. Anarquistas e socialistas hegemonizavam as organizações operárias e atuavam segundo os seus preceitos - os socialistas priorizando a luta parlamentária e os anarquistas a ação direta. Essa militância era diretamente proporcional ao descaso das autoridades em relação às condições de vida dos trabalhadores.

Ao longo dos primeiros vinte anos do século $\mathrm{XX}$ os trabalhadores expuseram às suas necessidades por meio de protestos nas ruas de Buenos Aires. ${ }^{15}$ Nestes anos se sucedeu uma série de conflitos que acabaram em conflitos entre as autoridades e os trabalhadores, com grandes prejuízos materiais e humanos para estes últimos. Só para mencionar os confrontos mais importantes, temos a Greve geral de 1902, a Greve de Inquilinos de 1907, a Semana Vermelha de 1909, a Repressão do ano do Centenário (1910), as eleições gerais de 1916 e a Semana Trágica de 1919. Isso para mencionar somente os conflitos na cidade de Buenos Aires, deixando de lado conflitos menores, como greves, boicotes e outras formas de luta e resistência desenvolvidas durante todo o período.

A intelectualidade e os principais partidos políticos tomaram diversas atitudes ante esta situação, porém é evidente que a questão trabalhista não podia ser negligenciada. Se existiu uma corrente que entendia que a única saída consistia em reprimir e disciplinar os trabalhadores à força, outros compreenderam a mudança significativa acontecida na sociedade argentina. Os trabalhadores não podiam continuar a ser ignorados e os seus problemas deviam ser considerados, correndo o risco de que o conflito dificultasse a continuidade do modelo agroexportador. De fato, a década de 1920 é uma década de poucos conflitos e de incorporação dos trabalhadores à vida social e política da Argentina, de uma maneira parcial e incompleta, porém suficiente para diminuir significativamente o nível dos conflitos.

É impossível esquecer a violência da repressão nos primeiros anos do século XX. Desde as leis de repressão social como a já mencionada Lei de Residência de 1902, a Lei de Defesa Social, de 1910, até as brutais repressões por parte das autoridades e grupos paraestatais que atuaram na Semana Trágica. Porém, esta não foi a única forma de abordar a "Questão Social". De fato a outra corrente de pensamento foi a que acabou colaborando para a transformação da sociedade argentina muito mais significativamente 
ao estimular a inclusão do trabalhador como cidadão e como membro pleno da sociedade.

Os conflitos sociais que se sucederam nos primeiros anos do século $\mathrm{XX}$, produto da falta de interesse com a vida operária por parte dos empresários e empreendedores e a prática repressiva aplicada pelas autoridades encarregadas da ordem e da segurança interna eram, evidentemente, insuficientes para atender à cada vez mais moderna organização do trabalho e da produção. Era óbvio que a industrialização argentina dependia da agroexportação e ainda estava condicionada pelo valor da moeda, o que dava uma grande instabilidade à produção local. Além do mais, temos que pensar num sistema produtivo baseado no uso extensivo da mão-de-obra, na baixa qualificação do trabalhador e numa alta rotatividade, mas mesmo assim era cada vez maior o número dos que dependiam de um salário e que estavam vinculados à produção fundamentalmente de bens de consumo para o mercado interno.

A repressão, por si só, não podia dar conta da cada vez mais complexa e diversificada produção e de um mercado de trabalho cada vez mais sofisticado. Nesse contexto uma série de analistas e políticos darão a sua contribuição na análise e na tentativa de incorporar o trabalhador à sociedade, não o deixando de fora. No interior do operariado existiam vários grupos ideológicos com propostas diferentes. Se os anarcosindicalistas ${ }^{16}$ tinham uma proposta revolucionária, os socialistas ${ }^{17}$ encarnavam o pólo reformador, sendo que além dos sindicatos independentes havia os sindicalistas revolucionários ${ }^{18}$, que, durante o governo de Hipólito Yrigoyen, ${ }^{19}$ foram cada vez menos revolucionários, aproximando-se cada vez mais das políticas oficiais.

Várias foram as tentativas de incorporar os trabalhadores e diminuir a quantidade de conflitos trabalhistas que tanto dificultavam a continuidade do processo produtivo, como a exportação de produtos primários. Entre 1900 e 1920, além de aparecer uma série de estudos e informes sobre a situação dos trabalhadores, nos deparamos com projetos e instituições que tentariam dar conta da questão social, sem deixar de lado definitivamente as táticas repressivas.

Os informes são múltiplos e têm as origens mais diversas. Em todos os casos existe uma forte coincidência sobre as más condições de vida e trabalho e do alto custo de vida entre os trabalhadores de Buenos Aires. Entre os redatores de informes sobre as condições dos trabalhadores nos depararemos com um bom número de operários que pretendiam chamar a atenção para os seus próprios problemas e preocupações. ${ }^{20}$ Isto é lógico e não tem muito de original. O mesmo poderíamos dizer em relação a indivíduos 
de outros grupos sociais que pela sua posição política fazem referência à situação do operariado como forma de atingir ao governo ou de mobilizar a sua própria base de apoio. $^{21}$

O que entendemos que é mais interessante é o tratamento dado por membros das elites a esta questão. De fato, desde inícios do século XX a questão social, seja pela sua virulência, seja pela exposição das chagas da grande exploração ou até pela proximidade das moradias dos abastados e dos pobres no centro da cidade de Buenos Aires $^{22}$, o certo é que se inicia uma onda de preocupação com as condições de vida dos trabalhadores. O primeiro informe a ser publicado neste sentido foi o de Juan A. Alsina, Diretor do Escritório da Imigração. ${ }^{23}$ O Informe de Alsina foi desenvolvido a instâncias do então Ministro do Interior, Joaquín V. González, conhecido pelas suas posições favoráveis a uma indústria que complementasse a agroexportação. González entendia que uma condição central para o desenvolvimento do setor estava na pacificação e regulamentação das relações entre Capital e Trabalho, sendo que a repressão poderia ser utilizada como uma forma de coibir os dirigentes sindicais e as tentativas de organização.

A partir dos informes ${ }^{24}$ encarregados aos funcionários do Ministério do Interior, nesse mesmo ano foi apresentada a Lei Nacional do Trabalho, primeira tentativa de intervenção estatal nas relações entre Capital e Trabalho. Apesar das boas intenções, a lei continha elementos que não satisfaziam nem aos trabalhadores, nem aos industriais. Os trabalhadores reclamavam dos limites à organização e à ação dos sindicatos, e os industriais a achavam muito avançada pelo fato de reconhecer as oito horas de trabalho diárias e a semana de seis dias. De todas as formas, o Projeto de Lei acabou fracassando, em grande medida, pela conjuntura política desfavorável aos homens do Governo de Júlio Argentino Roca, que estava em fim de mandato e no fim da sua vida política, e pelo fato de não contar com o apoio das organizações patronais, como a União Industrial Argentina (UIA). Mas não foi um projeto sem importância e foi discutido ardorosamente, antes e depois da sua derrota no Congresso, marcando uma virada no tratamento da questão social, passando de um caso de polícia a um problema econômico e social. ${ }^{25}$

De fato, como consequiência desse debate, uma série de reformas foi proposta, e algumas delas aprovadas, como a lei que regulamentava o trabalho feminino e infantil, a lei de acidentes de trabalho e outras. Mas o principal resultado foi a criação do Departamento Nacional do Trabalho (DNT) em 1907. O DNT, com limitadas 
possibilidades de ação e intervenção e visto como mais inofensivo, tinha unicamente funções técnicas e informativas. Não teve uma atuação relevante na transformação das relações entre Capital e Trabalho. Problemas políticos, falta de harmonia com os distintos segmentos do Estado dificultaram o seu acionar e a consecução de resultados concreto, porém foi produzido um sem-número de informes e análises sobre o operariado na Argentina.

A segunda década do século XX foi pautada pela abertura política e a instauração do voto universal (masculino), obrigatório e secreto, e pelas turbulências econômicas produto da Primeira Guerra Mundial. De alguma forma a questão social ficou novamente restrita aos conflitos diretos entre Capital e Trabalho e levou a que se projetassem sobre o Governo de Hipólito Yrigoyen, eleito em 1916, todos os anseios de reforma dos trabalhadores. Em certa medida, a eleição postergou os conflitos, porém os agravou posteriormente, quando o governo de Yrigoyen não conseguiu atender as demandas operárias. ${ }^{26}$ Assim, uma série de conflitos violentos se desataram no fim da década e nos inícios dos anos vinte. ${ }^{27}$

Porém, não podemos deixar de vincular a transformação da democracia argentina de uma democracia restrita numa democracia de massas, desde 1912, como uma conquista dos próprios trabalhadores. O fato é que só uma parcela deles podia usufruir as reformas que eram produto das lutas anteriores e do conjunto, devido ao fato de que muitos deles não aderiam aos métodos democráticos, como acontecia com os anarquistas e os sindicalistas revolucionários. Unicamente os anarquistas e trabalhadores que se vinculavam com os radicais puderam tirar proveito destas lutas prévias. Como produto da importância dada pelos socialistas às táticas parlamentaristas, eles conseguiram construir bancadas significativas desde as eleições de 1912.

Os sindicalistas revolucionários, mesmo quando não participavam eleitoralmente, diferiram dos anarquistas no fato de manter relações, e quase sempre boas, com o governo de Yrigoyen. Grande parte das conquistas operárias do período se deviam muito mais à intermediação deste grupo em determinados conflitos e ao acesso direto que tinham às altas esferas do governo, que às táticas socialistas. Para o governo de Yrigoyen era muito mais proveitoso atender às demandas deste grupo, desautorizando aos reclamos socialistas e mostrando que o crescimento eleitoral não se traduzia em conquistas para os trabalhadores.

A sanção definitiva de um Código Trabalhista em 1921 acabou coroando as lutas operárias prévias e sagrou a importância dos Sindicalistas Revolucionários para o 
Governo Yrigoyen. A Sociedade Argentina de 1921 tinha mudado significativamente, não era mais uma sociedade que olhava para o trabalho como um elemento menor. Agora os trabalhadores tinham a quem e como reclamar, embora isso não fosse totalmente certo, mas pelo menos a sua presença era considerada central, o ponto de as suas relações profissionais e políticas serem legisladas no interior da sociedade argentina.

FERRERAS, Norberto O. The Contemporary Argentine Society Constitution. Society and Work between 1880 and 1920. História, São Paulo, v. 25, n. 1, p. 170-181, 2006.

Abstract: This article studies the relationships between the working class formation and the modernization process in contemporary Argentina. The State made some arrangements for incorporating the former immigrants, who became workers, in the Argentinean society. That was no possible without worker's struggle. In this case they were recognized as members of Argentinean society. In some way this struggle has limited the Oligarquical State restoration possibilities.

Keywords: Argentina, Workers, Social Legislation, Repression.

Artigo recebido em 09/2006. Aprovado em 10/2006.

\section{NOTAS:}

\footnotetext{
* Prof. Adjunto de História da América, Depto. de História, Universidade Federal Fluminense (UFF), Niterói, RJ. Correio eletrônico: ferreras@ vm.uff.br.

${ }^{1}$ Para um resumo dos projetos e programas dos intelectuais no período de organização nacional pode ser consultado o Capítulo 7, Reconsidering the Repulic de ADELMAN, Jeremy. Republic of Capital. Buenos Aires and the legal transformation of the Atlantic World Stanford, Stanford University Press, 1999.

${ }^{2}$ Nesses dois anos há uma série de eventos que consolidam a Organização Nacional: a definição da relação com os povos originários com a Campanha ao Deserto, que é praticamente uma guerra de extermínio e que amplia as fronteiras produtivas até o limite norte da Patagônia; é derrotada a última sedição federalista contra o governo central; a cidade de Buenos Aires é transformada em Capital Federal e portanto cidade neutra e controlada pelo governo central; e finalmente define-se a relação entre as oligarquias regionais com a eleição de Julio Argentino Roca como presidente.

${ }^{3}$ Sobre a economia argentina no período, vide Cortés Conde, Roberto. La economía argentina en el largo plazo (Siglos XIX y XX) Buenos Aires: Ed. Sudamericana, 1997, especialmente o primeiro capítulo: Un siglo de crecimiento económico de la Argentina (Algunas observaciones empíricas). Para a crise política de 1890 e o processo político do período ver ROCK, David. El Radicalismo Argentino. 1880-1930. Buenos Aires: Amorrortu, 2001.

4 Numa carta enviada a Karl Marx por Raymond Wilmart, deparamo-nos com a percepção de impossibilidade da mobilização dos trabalhadores, lembrando que Wilmart era um exilado da Comuna de Paris. A carta de Wilmart está no International Instituut Voor Sociale Geschiedenis (IISG), Amsterdã, INVENTAR DES MARX-ENGELS NACHLASSEN, BRIEFE AN MARX, D. 4604. A.
} 
${ }^{5}$ Vide HALPERÍN DONGHI, Túlio. ¿Para qué la inmigración? Ideología y política inmigratoria en la Argentina (1880-1914)' In: HALPERÍN DONGHI, T. El espejo de la Historia. Problemas argentinos y Perspectivas latinoamericanas. Buenos Aires: Sudamericana, 1987, pp. 211 e 212.

${ }^{6}$ A obra que mais claramente trata desta questão é CAMBACERES, Eugenio. En la sangre. Buenos Aires: Colihue, 1988 ( $1^{\mathrm{a}}$ ed. 1887).

${ }^{7}$ Vide ARGERICH, Antonio. ¿Inocentes o culpables?. Buenos Aires: Hyspamerica, 1985 (1 $1^{\mathrm{a}}$ ed. 1884).

${ }^{8}$ Vide MARTEL, Julián (Pseudônimo de José María Miró). La Bolsa. Buenos Aires: La Nación, 1909 (1 ${ }^{\text {a }}$ ed. 1891).

${ }^{9}$ Para uma apresentação da posição dicotômica da literatura do período, VILLANUEVA, Graciela. La imagen del inmigrante en la literatura Argentina entre 1880 y 1910. In: "Amerique Latine Histoire et Mémoir, $N^{\circ} 1$ Migrations en Argentine. Paris: Université Paris VIII, 2000.

${ }^{10}$ Para maiores detalhes sobre a fundação da Federação Operária Argentina, vide MAROTTA, Sebastián. El Movimiento Sindical Argentino. Buenos Aires, Libera, 1975 (1ª ed. 1960), v. I, pp. 124 e 132.

${ }^{11}$ Para acompanhar a evolução dos salários Vide o Capítulo III de FERRERAS, Norberto O. No País da Cocanha: Aspectos do Modo de Vida dos Trabalhadores de Buenos Aires (1880-1920). Campinas, 2001. Tese de Doutorado defendida na Pós-graduação em História Social da Unicamp.

${ }^{12}$ Para os dados de crescimento populacional na Argentina e em Buenos Aires, vide República Argentina. Tercer Censo Nacional de la República Argentina. 1914. Buenos Aires: Taller Gráficos de L. J. Rosso, 1917.

${ }^{13}$ Para maiores dados sobre o aumento do preço dos principais consumos operários, vide FERRERAS, Norberto O. Evolución de los principales consumos obreros en Buenos Aires, 1880-1920. In: Ciclos en la Historia, la Economía y la Sociedad n22. Buenos Aires: Facultad de Ciencias Económicas, UBA, 2001; e para mais dados sobre as taxas de desemprego e o aumento do número de crianças e mulheres que ingressavam no mercado de trabalho, Capítulo III de FERRERAS, Norberto O. No País da Cocanha... Op. cit.

${ }^{14}$ Poucos anos depois, em 1904, a FOA daria lugar à Federación Obrera Regional Argentina (FORA), de caráter anarquista, muito mais conhecida por esse nome do que pelo de FOA.

${ }^{15}$ Uma interessante análise do surgimento do protesto social no Capítulo 1 de LOBATO, Mirta e SURIANO, Juan. La protesta social en la Argentina. Buenos Aires: FCE, 2003; e para os conflitos organizados pelas condições de vida dos trabalhadores, vide FERRERAS, Norberto O. O cotidiano dos trabalhadores de Buenos Aires (1880-1920). Niterói: Eduff, 2006.

${ }^{16}$ Para maiores detalhes sobre os anarquistas no período, SURIANO, Juan Anarquistas. Cultura y política libertária en Buenos Aires, 1880-1910; e ZARAGOZA, Gonzalo. Anarquismo argentino (1876-1902). Madrid: Ed. de la Torre, 1996.

17 Ver CARRERA, Nicolás Iñigo. Documentos para la Historia del Partido Socialista. Tandil: IEHS, 1996.

${ }^{18}$ Ver BERTOLO, Maricel. Una propuesta gremial alternativa: el Sindicalimo Revolucionário (19041916). Buenos Aires: Ceal, 1993; e DEL CAMPO, Hugo. El 'Sindicalimo Revolucionário' (1905-1945). Buenos Aires: Ceal, 1986.

19 Hipólito Irigoyen (1852-1933), fundador da Unión Cívica Radical, foi o primeiro presidente da Argentina eleito pelo voto universal, secreto e obrigatório. A sua presidência marcou o fim dos governos conservadores e o início da política de massas na Argentina.

${ }^{20}$ As distintas tendências operárias do período tomaram esta prática e divulgaram os seus informes como forma de sensibilizar à opinião pública. Entre eles mencionamos os informes dos socialistas. MUZILLI, Carolina. El trabajo femenino. Buenos Aires: L. J. Rosso y Cía, 1916; e PATRONI, Adrián. Los trabajadores en la Argentina Buenos Aires: Imp. de Chacabuco 664, 1897. Assim como o informe do Sindicalista Revolucionário BOSIO, Bartolomé. Un fenómeno de la economía capitalista ¿Porqué es caro el pan? Buenos Aires: Sindicato de Obreros Ebanistas, Similares y Anexos, 1920.

${ }^{21}$ Entre os militantes que tomaram as dores dos trabalhadores, mas que não faziam parte deste grupo social, podemos mencionar o socialista PALACIOS, Alfredo. La Miseria (en la República Argentina). Buenos Aires: José Larrañaga y Renovales, 1900. Tesis de doctoramiento en abogacía rechazada; e a Sindicalista Revolucionária CONI, Gabriela L. de Proyecto de Ley del trabajo de la mujer y del niño en las fábricas Presentado a la Intendencia Municipal de Buenos Aires. Buenos Aires: S/E, 1902.

${ }^{22}$ Ver os Capítulos Buenos Aires 1880-1920: Uma metrópole em construção e A Buenos Aires dos trabalhadores em FERRERAS, Norberto O. O cotidiano dos trabalhadores... Op. cit.

${ }^{23}$ Alsina, Juan. El Obrero en la República Argentina. Buenos Aires: Imprenta Calle de México 1422, $1905.2 \mathrm{v}$. 
${ }^{24}$ BIALET MASSÉ, Juan. Informe sobre el estado de la Clase Obrera.. Madrid: Hyspamérica, 1989 (1 ed: 1904). 2 v. STORNI, Pablo. La industria y la situación de la clase obrera en la Capital de la República. In: Revista Jurídica de Ciencias Sociales, v. II, $\mathrm{n}^{\text {os }}$ 4, 5 y 6 Buenos Aires, 1908.

25 Para maiores detalhes sobre a evolução dos debates sobre a Lei Nacional do Trabalho, ver ZIMMERMANN, Eduardo. Los Liberales reformistas. La cuestión social en la Argentina, 1890-1916. Buenos Aires: Ed. Sudamericana, 1995.

${ }^{26}$ Para compreender qual era a forma em que Irigoyen compreendia a questão social, ver FALCÓN, Ricardo. Políticas Laborales y relación Estados - Sindicatos en el gobierno de Hipólito Yrigoyen (19161922). In: SURIANO, Juan. La cuestión social en la Argentina. 1870-1943. Buenos Aires: La Colmena, 2000.

${ }^{27}$ Para uma crônica desses anos e, em especial, do 'triênio vermelho' de 1921 a 1923, ver DOESWIJK, Andréas. Entre Camaleões e Cristalizados. Os anarco-bolcheviques rioplatenses 1917-1930. Campinas, 1998. Tese de Doutorado em História Social da Unicamp. 